\title{
Legal and Cover Restrictions
}

\author{
by Malcolm Aickin*
}

\section{Introduction}

In his book, Limits of insurability**, Dr. Baruch Berliner identifies and describes a number of criteria or dimensions of insurability. He then argues that these should be plotted as independent variables on orthogonal axes in a 9 dimensional Euclidean space.

This is an oversimplification since some of the variables are not truly independent, as Dr. Berliner himself makes clear. These is also only partial understanding of the mathematics of a single dimension; if one insurer considers risk $A$ to be more risky than risk $B$ a single insurability criterion such as to make risk $A$ uninsurable and risk $B$ insurable, and another insurer takes exactly the opposite view, this not only proves that both A and B are in the 'grey' area between insurability and uninsurability as Dr. Berliner suggests, but also that the concept of the insurability criteria itself is 'grey'. Although this may simply be based on subjective difference arising from the different perspectives of the observers it more probably hides confusion over the criterion itself. It may in fact be a compound of two or more separate factors and in reality different insurers give different emphasis to the different components. Perhaps as in modern physics we should not be attempting to break the process down into discrete factors but to build a unified field theory.

Several of the dimensions of insurability identified by Dr. Berliner, particularly legal and cover restrictions, do not define the parameters of a risk. Rather than being dimensions of a risk, in the same way as frequency or moral hazard, these should be considered as operators which define the shape of the insurable volume within the vector space. Alternatively they can be considered as acting upon the dimensions to bring a specific risk within the volume of insurability.

\section{Cover restrictions}

No risk is insurable without cover limitations to define the risk which is transferred. Cover limitation is a tool used by insurers to make a risk which is otherwise uninsurable acceptable by isolating insurable features. One can look at this either as eliminating

* Director, ERAS (International) Ltd., London.

** Prentice Hall, Englewood Cliffs, N.J., USA, 1982. 
particular areas which are uninsurable or as identifying particular risks so that they can be quantified and a premium calculated. I would argue that premium was really synonymous with cover limitation, it is simply a readily identifiable component of the set which comprises cover limitations. Premium is readily interchangeable with cover restrictions. For example third party cover in motor insurance attracts one rate, third party fire and theft a higher rate and fully comprehensive cover a higher rate again.

Cover limitations are imposed internally by insurers. It is in describing cover limitations that an insurer exercises his professional skill. First of all, in assessing the dimensions of the risk, secondly in setting the cover restrictions to bring the risk within the insurable space, thirdly to set the premium according to the modulus of the risk, or distance from the origin, requiring transformation of the dimensions to polar co-ordinates.

\section{Legal restrictions}

Legal restrictions back-up and overlap with coverage limitations. Like cover restrictions they impinge on the other criteria and they are rather complex. It is trivial that a particular risk is either insurable or not at law. Legal restrictions have negative as well as positive effects and are wide ranging to the point of being all pervasive.

Legal restrictions may be used to reinforce uninsurability for example on the grounds of public policy. They may also be used to enforce insurability in areas insurers otherwise would consider uninsurable. They can be used in the public or national interest to protect a state monopoly insurer from competition or national insurers from overseas competition and the economy from a drain of hard currency. Finally they can be used in a whole variety of ways to protect the insurance buying public. They can prevent insurers taking too much advantage from the exercise of their professional skill to the detriment of insureds or they may be used to prevent insurers overstretching themselves. They can be considered as a brake which can be externally imposed upon Insurers to restrict their freedom in imposing cover restrictions.

Legal restrictions can be classified in two groups depending upon their origins which are either in legislation or in judicial interpretation either of the law or the insurers attempts to define cover through cover restrictions.

Because legal and cover restrictions overlap they are most effective both from insurers and the public policy perspective. When they act in opposition they can, in the extreme, make insurance impossible.

\section{Chemical liabilities}

Having introduced some points of theory it is time to look at practical effects. I intend to do so in relation to chemical liabilities and particularly environmental liabilities. These problems are the major liability challenge for the remainder of this century and beyond. As far as strategic planning is concerned, the major challenge seems a good as well as exciting example to consider.

First of all a definition of what I mean by a chemical liability is in order. Chemical liabilities are those where bodily injury or property damage is caused by a chemical reaction rather than physical action: here we must consider intangible as well as tangible property rights. 
The majority of liabilities are caused by physical damage. The most serious and challenging of these is the collapse of large structures including dams. Even these are now fairly well understood and controlled.

Perhaps we should look at how physical and chemical damages differ. If we look at explosion as typical of physical damage, then we can see that the damage is over and done with fairly quickly. Even if, as in Flixborough, damage is spread over a wide area, it occurs at speeds approaching the velocity of sound. If we look at fire as a chemical damage, we see that the damage occurs over much longer period of time. The train at Missisauga burnt for several days. Most chemical liabilities occur through reaction at ambient temperature and are slower than fire.

The second characteristic of chemical liabilities is that quite small quantities of material can cause widespread damage. Bhopal is a case in point, a similar quantity of masonry or metal discharged in a conventional explosion or even release of super-heated steam, would not have caused the same widespread devastation. This is of course why chemical warfare is so awesome.

\section{Absence of detailed knowledge}

At present we have only a very poor understanding of these toxic reactions; a case is made against the use of lead in petrol because of the toxic effects. The chemistry of what happens to the tetra-ethyl lead and tetra-methyl lead additives is well known and once they have left the exhaust in air they are converted fairly rapidly to lead sulphate and lead dioxide, through a short-lived lead amonium sulphate. We know that lead dioxide and lead sulphate are insoluble and virtually unassimilable, they cannot be responsible for the toxic effects claimed. It follows therefore that there may be another unidentified lead species present which is extremely unpleasant.

We are therefore in an area which is at the fringe of our scientific knowledge. There is considerable thought and attention directed to the glass-house effect. Carbon-dioxide is the product of respiration of all living things, other than perhaps a few exotic sulphur bacterials. Carbon-dioxide is used by plants in photosynthesis and oxygen is released. Most photosynthesis occurs in the tropical rain forests. The tropical rain forests are being depleted rapidly in an uncontrolled fashion through cut and burn agricultural techniques and to provide the hard wood doors which are now the distinguishing mark of the farmer council house bought by its farmer tenant. The result is that less photosynthesis takes place, as a consequence the carbondioxide concentration in the atmosphere builds up. This it is believed may reduce the heat loss into space: hence the glass house effect. This will produce an overall warming and a Brazilian group have argued that this will result in the melting of the polar ice-caps and the consequent raising of sea level by 80 feet. The change in mean annual temperature required is fairly small: in the region of 3 degrees centigrade.

Geologists are now predicting a new ice age and some argue that the initial signs of such a cooler period are already present. We do know from the fossil record that the cooling required for the onset of a major ice age is only a reduction of about 3 degrees centigrade in mean annual temperature. An almost imperceptible change when compared with the annual temperature range. 
One could argue that these two effects will cancel each other out and that cut and burn farming will actually save us from the next ice age. Although, since I wrote the first version of this paper, there has been an Open University programme drawing this connection, it is of course mere speculation. No one will be able to establish the truth - at least not in our lifetime. I use this simply as illustrative of our lack of knowledge in this area.

Lack of knowledge creates difficulties for an insurer. The assessment of the dimensions of insurability is of greater difficulty. As a result the setting of cover limitations is of critical importance.

Lack of knowledge of course creates difficulties in the legal area. If one took the case against lead in petrol to Court, the best verdict one would expect would be a 'not proven' verdict under Scottish law.

\section{Difficulty in establishing causation}

Causation in chemical liability is much more difficult to prove than with physical liabilities. If one is shot the bullet is still around and available for ballistic examination. If one is poisoned with cyanide, the prussic acid does not remain for examination. It has reacted with the oxygen-binding site in the haemoglobin; this is after all how cyanide kills.

An example of the difference is the death of Georgie Markov. He was stabbed by an umbrella whilst walking over London Bridge and died mysteriously, believed to be the handiwork of the Bulgarian Secret Service.

A post-mortem examination revealed a small hollow spherical pellet with two holes in it. The pellet was recovered and subjected to intensive scrutiny and a huge amount of detail is known about it. It is believed to have contained a small amount of toxin, however no trace of the toxin was found and it has not been identified. The exact nature of the toxin is the subject of much speculation and surmise. The toxin from the botulism organism has been suggested as the lethal agent.

\section{Development of law}

The law and particularly the common law has developed through dealing with physical problems. As a result it is ill-equipped to deal with chemical liabilities and needs to develop in order to do so. Chemical liabilities therefore, lie on the cutting edge of both scientific and legal development; as a result, they are particularly interesting.

As knowledge advances in this area the law will develop, changes will occur in both statute law and common law. In the early ' 70 s New York State passed a law forbidding the insurance of environmental liabilities other than those caused by a sudden and accidental event. This was based on the general assumption that if pollution was not sudden and accidental it had to be wilful; it would of course be against public policy to provide insurance for the wilful polluter.

We now understand that pollution can occur gradually, i.e. over an extended period of time without any wilful intent on the part of the polluter to cause damage. Many corporations discharged material to the environment believing it to be harmless and were completely taken 
aback to discover that damage resulted. During this period insurers developed techniques for defining cover limitations to contain the risks within an insurable volume. There was a parallel development in legal thinking which led to a requirement for gradual pollution cover for some activities in the U.S. under Federal Law and the New York statute prohibiting such insurance has been repealed. We have in fact almost gone to the opposite extreme and consider that such past acts ought to be insured retrospectively even if there is a known problem or those responsible acted without proper regard to the knowledge of the time. For example, one should have known that 55 gallon drums left in the open would go rusty.

Because investigation and identification of chemical agents is quite different from the investigation of physical agents the law on causation will develop. There has already been an attempt at such development in Minnesota. In my view this particular change went too far and in effect adopted the res ipsa loquitur argument to the ridiculous extent that one could argue: I have cancer, cancer may be caused by goo, you handle goo, so you must have let the goo escape and so are liable for my cancer.

I am delighted to say that Minnesota has now repealed this part of the legislation along with Joint and Several and retro-active liabilities. They did so in part because I excluded liability under certain sections of the Act from my policy form. This is a clear example of legal requirements and coverage restrictions working in opposition to the extent that insurance becomes impossible.

It is important for insurers to be active in this area so that coverage limitations and legal requirements develop and work in harmony rather than in conflict. This requires that insurers have a good understanding of the problems and can address them in terms of the capabilities of the insurance industry to define appropriate cover limitations.

\section{Public expectations of insurers}

There is a general public perception that insurers can and should provide three separate functions in the environmental area. First that they should act as a surrogate regulator. Quite clearly insurers cannot do this because the economics of the insurance industry mean that they cannot afford to do so, apart from the conflict this would create between the insurer and insured. An insured simply will not make a clean declaration to an insurer if he knows that information could pass into the public domain in an immotive area for use as a Treasure Island Map by Plaintif's Lawyers.

It is in any case unreasonable to expect an insurer to act as a surrogate area. His professional skill lies in setting cover limitations, including premium, such that a risk falls within the volume of insurability. This is quite distinct and should in no way be confused with falling within public acceptability. Motorists driving without seat belts are insurable. Prior to the introduction of seat belt laws motorists were insured with no discrimination as to whether they wore seat belts.

The second area in which insurance is expected to provide a service to the community is in providing incentives through the premium structure for good management and environmental practice. This too is unrealistic. In the Bhopal tragedy five independent safety systems failed. With hindsight many experts say that this failure was inevitable. If one accepts a one in 
ten chance for failure of an individual safety system, which is probably much higher than the real probability, then Bhopal was $10^{5}$ times more dangerous than it should have been. It is simply impractical for any insurer to increase a premium 100,000 times.

The third function which the insurance industry is expected to perform is to provide a safety net when things go wrong so that there is sufficient money available to compensate victims. In some ways this is in conflict with the other two expectations. If in its regulation or coertion role an insurer refuses to provide cover for a particular insured, the insurer is failing to provide the safety net. Although I am sceptical that insurance can make an individual drive better, this seems a notion worth fostering. It is a notion in direct conflict with the safety net approach.

The second problem with the safety net approach when dealing with chemical liabilities is that the insurance industry may be unable to provide a safety net of sufficient strength to be effective in all circumstances. Since breakage of the net would in practice mean breakage of the insurance, the insurance industry should not be asked to extend the safety net in circumstances where it is or should be expected to fail.

It is unclear what the eventual cost of the Bhopal tragedy will be. Speculation on the amount may also be counter-productive. What seems clear is that the $\$ 200$ million available in insurance will be inadequate. It also seems probable that the loss will exceed the $\$ 350$ million Union Carbide are believed to have been offered but decided against purchasing. It also seems clear that had the tragedy occurred in a western country in the Old or New World, as distinct from the Third World, the cost would probably be greater. Further it is clear that liability limits as high as $\$ 200$ million are not available in todays market place. It should then be obvious that the insurance industry cannot and should not take on this entire burden itself, it simply does not have the resources to do so.

\section{Breakdown of insurance when legal and coverage restrictions are in conflict}

I said that I would revert to overstretch. In the first session it was suggested that looking to the U.S. Government as the insurer of last resort was an admission that the insurance industry had overstretched itself. I do not consider this should be viewed in some way as an admission of failure, but rather as a position of strength.

The insurance industry does have an important contribution to make in these areas. The availibility of insurance, and possibly insurance itself is breaking down because legal and cover requirements are working in opposition rather than in concert. Insurers should be active in environmental matters.

The present legal position in the U.S. means that environmental problems are outside the insurable volume. The law in the form of statute, regulation and judicial decision are acting against the cover restrictions imposed by insurers so as to make them unworkable. However environmental problems are not uninsurable in other territories, indeed in many they are given freely as part of general liability coverage and are neither evaluated nor priced. We should give more serious consideration to the problem. The Green revolution is coming and we need to be prepared for it. We should not assume that the same mistakes which have been made in the U.S. will inevitably be made elsewhere: ther is a need of becoming actively 
involved in an attempt to arrive at more acceptable solutions where law makers and insurers work together. It must be in insurance industry's long term interests to ensure that a legal environment in which insurance is possible is maintained.

\section{Difference between U.S. and Europe}

We should not assume that where the U.S. leads, the rest of the world will automatically follow. I believe there are problems which have occurred in the U.S. which will not occur elsewhere.

There are great cultural difference between the United States and Europe. Most of the British Isles is mapped down to $1 / 5,000$ scale and the entire country is mapped to $1 / 10,000$ scale. It would be impossible to find a point on one of those maps which was not intimately familiar to at least half a dozen people. Vast tracts of the United States have not been mapped in detail and there are large areas which are not regularly visited by anyone. When visiting a mid west State a presidential candidate asked what happened to the rubbish and was told they just kicked it around till it wasn't there any more!

In Europe the Industrial Revolution occurred after we had full population. If you were an industrialist in Bolton you hoped to remain in Bolton, and that your son would succeed you in the business; as a result there would be considerable incentive to keep Bolton an attractive place to live. In America the Industrial Revolution occurred prior to full population. As a result there was always plenty of space in which to kick the trash around until it disappeared; and if a place became too unpleasant there was always somewhere fresh to move to. America has an immigrant population. First generation Americans have broken their family ties and roots and they did not expect their children to develop these ties. As a result, if you were born in Akron, Ohio, one of your first and overriding ambitions in life was to get out of Akron and go somewhere else, where, did not particularly matter. As a result there was very little incentive that Akron should remain a pleasant place to live, it was fairly unpleasant anyhow.

In America if you could persuade a major corporation or even a rich industrialist to part with a buck or two to let you dispose of his unwanted waste this was all to the good and part of the great enterpreneurial spirit which made the country what it is. This did not happen in the same way on this side of the Atlantic where you entrusted waste disposal, if you entrusted it to anyone, other than the local authority, to someone you went to school with, played cricket with, or at least hunted with.

In Europe and certainly in the British Isles we depend upon the rain fall for our drinking water supplies. Even where we have wells they tap surface waters which are replenished by the rain fall. In contrast the Americans are heavily dependent upon underground water supplies and not upon rain fall. Ground water contamination is therefore much more sensitive in the United States than it is in Britain.

All of these factors have contributed to the waste site problem in the United States and I do not think that a waste site problem of anything like the same proportions will occur in Europe. 


\section{Development of new liabilities}

The development of new liabilities will lead to the requirement for new cover provisions. It is essential to realise on the part of both legislators and the insurers that these developments must be prospective and not retroactive. They also require a deep understanding of the problems and a proper definition of the liabilities which they create.

Part of this understanding is to appreciate the costs involved in these problems. When I originally became involved with environmental liabilities I predicted that most losses would be in excess of $\$ 1,000,000$. Now that we are developing loss information this prediction is being borne out. Some insurers are critical, in terms of anti-selection, because of the absence of $\$ 50,000$ claims which they expect to see. They are not alone in failing to perceive the true catastrophic nature of the risk.

In facing this challenge we need close cooperation between insurers and law makers. We all need to understand that in the worst manifestations, chemical liabilities are too big to be insurable. That if they are forced upon the insurance industry the industry will be overstretched. In the catastrophic chemical accident we have to acknowledge that we are dealing with a societal problem and that society as a whole must shoulder the burden. We need to establish what level this should be transferred from an individual and his insurers to the State. Ideally we should do so before the major chemical catastrophe rather than in the panic and emotion of its aftermath.

On the first day of this seminar the question has been discussed about the usefulness of business games in Strategic Planning. I believe that a very beneficial use of such games is in disaster planning. To some extent the emergency services already indulge in such games. However these are generally restricted to the immediate emergency response. These games have not considered the long term outcome of a disaster, the rebuilding and compensation for damage and injury. I feel that it is important for the insurance industry that the aftermath should be played, and that insurance people should be involved in the game.

\section{Development of new cover limitations}

Probably the most important coverage limitation for an insurer is that he should be able to quantify his maximum exposure to loss. Only in this way can he make sure financial stretch does not become overstretch. An insurer needs to establish that in the worst case he will only have to pay $\mathrm{X}$ million. Establishing such a maximum is actually more important than the value of $\mathrm{X}$ itself. Joint and several liability is a device which erodes an insurers' protection of a ceiling per loss. Where this doctrine is applied to find a number of contributors to a problem joint and severally liable for its entirety, the full limits of each contributor's liability policy can be stacked together, thus increasing underwriters' maximum exposure to loss many times. Underwriters may be able to project themselves against this by the use of anti-stacking clauses of some kind. Perhaps along the lines of the Swiss pro rating claims clause for natural disasters mentioned by Dr. Nierhaus. An underwriter must attempt to protect himself from the theoretical situation where all contributors are identified. In practice of course, all the contributors will not be identified and so the underwriter must have over-protected himself.

The underwriter also needs some confidence that his anti-stacking clauses will stand up. Because the anti-stacking clause (the coverage restriction) is in conflict with the joint and 
several liability doctrine (the legal provision) it may be questionable that the anti-stacking clause will stand up if tested in Court. Here again, understanding and cooperation between insurers and law makers is essential.

The so-called triple trigger theory is another device which defeats attempts to control an underwriters' maximum exposure. It is worth looking briefly at this theory. Consider an insured who purchased a million dollar liability coverage in the early' $50 \mathrm{~s}-\mathrm{a}$ limit which at the time would be considered more than adequate. If, in the ' $80 \mathrm{~s}$ a claim is filed which goes back to the '50s policy, the limit is obviously inadequate because of the fall of the value of money over the intervening 30 year period.

One way to deal with this problem would be to link to inflation the limits of the original policy. This would then have the limit, not of $1,000,000$ dollars in the ' 80 s, but of say, $17,500,000$ dollars: $10 \%$ inflation a year for 30 years. Such an approach is fraught with difficulty in terms of increasing limits and reserves for both an insurer and his reinsurers.

The triple trigger theory is an alternative which overcomes the problem of fiscal drag. It also preserves the monetary units of each individual policy, wnich inflation linking would not do, but it allows a single loss to be spread over a number of policy years; it is quite uncontrolled in terms of increasing the maximum limit for loss. It, in effect, allows the loss to be spread over sufficient years to provide sufficient limits to satisfy the award. The Judges in the "Keene" case were clearly aware of this possibility. The cause they argued was that the insurance industry had adopted a standard policy which was inadequate to deal with the problems.

They expected the insurance industry to produce new cover limitations which would deal with the problem. This is how things should happen.

\section{The claims made policy}

The requirement for new cover limitations which is adequate to deal with the problems has led to the general introduction of the claims made policy. This introduction is not unopposed.

There are some who would argue that the claims made policy was in some way unfair or against public policy or incompatible with the basic principles of insurance and therefore should not be allowed.

These critics of claims made policies would argue that coverage is granted on the "pay as you go" system. Dr. Berliner argues that it is doubtful that such a system is compatible with the idea of insurance although his criticism is directed to 'pay as you go' rather than the 'claims made' concept. There are several good reasons for taking issue with this stance against the claims made policy. Whether they realise it or not insurers account on a"pay as you go" basis. I.B.N.R. provisions are quite inadequate to deal with problems such as asbestosis. If they were adquate there would have been long-running battles with the tax man over several years. As a result, current claims have to be paid for out of current income.

This means that it is wrong to argue that a claims made policy should have a cheaper premium than an occurrence policy. Whether the policy wording says so or not, most insurers have written and set premiums on a claims made basis for several years. The claims made policy merely puts what has been common practice into a formal coverage restriction. 


\section{Two types of claims made policy}

Claims made wordings have been used for the provision of environmental impairment liability cover. Particularly where coverage for gradual pollution is being given, the chemical reactions causing damage take place over extended periods of time. This makes the concept of occurrence useless in identifying a particular point in time. In consequence, the ideas of occurrence must be completely abandoned in setting coverage restrictions in order to contain the loss within a ceiling of maximum exposure.

In cases of environmental damage it is likely that many different claimants will be affected by the same discharge. It is important to ensure that all these claimants and all the possible claims resulting from the same cause should be treated as a single claim in order to contain the loss within a single limit. Thus, all claims must be driven back to a common cause and treated as a single loss.

Professional indemnity, malpractice and errors and omissions insurance have also been written on a claims made form. These are different from environmental impairment and chemical liabilities. In these types of coverage the claimants are normally restricted and well defined. It is also often possible to identify a point in time or a fairly short and precise period of time during which the cause of loss happened. If a surgeon leaves a swab behind during an operation, it is safe to assume this is not the result of a faulty surgical procedure when the swab would be left behind on every occasion that the operation was performed because its removal had been omitted from the defined steps of the procedure. In consequence one expects that this would only happen on one occasion to a particular patient. The claimants will be restricted to the patient and perhaps his immediate family and circle. In these circumstances it is not necessary to completely abandon the frame of reference of occurrence policies.

The second variation of the claims made policy is now being adopted, together with an absolute pollution exclusion for general liability coverage in the United States.

The adoption of a claims made wording is a United States development which will spread elsewhere. It does not arise as a result of the American culture and the litigious nature of its people. These may have helped speed the development along but they are not the underlying cause. The underlying cause is overstretching of the insurance industry. Whether this arises through faults internal or external to the insurance industry is irrelevant. The plain fact is that insurers, the insurance industry, is no longer able to provide a limit which is in excess of the largest possible loss. We have to recognise this and we make sure that society recognise this as well. We need to be certain that legal and cover provisions act in concert to avoid the insurance industry being overstretched.

It is important to distinguish between the two types of claims made policy. The first type I have mentioned, that which completely abandons the occurrence frame of reference, is at present the least common type of coverage granted. I believe that to avoid any confusion this should be given a different name for example, First Notification of Loss, which would avoid any misunderstanding or ambiguity and would make it quite clear to an insured which type of coverage he was obtaining. It is potentially disastrous if Court precedence development for one type of coverage is applied to the other. The second type, that I suggest retains the name "claims made", is based on some aspects of occurrence philosophy.

Many insureds are comfortable with this type of approach which has served them well for many years. They expect to see the approach and the legal precedents continued. Where this is 
appropriate there is no reason for insurers to deny their customers their expectations. However, in other areas there are good reasons, which I have tried to outline, why the occurrence framework is completely inappropriate. It is essential in these circumstances that the type of policy I have called "First Notification of Loss" avoids the occurrence frame of reference completely.

\section{Conclusion}

I have analysed chemical liabilities and the need to develop new coverage and legal restrictions to deal with them; it is however, perhaps worth pointing out that the insurance industry has in some fashion been dealing with these problems for a long time and that they are not perhaps as new as we like to think. Products liability coverage was first developed in response to a need. This need came from furriers who were being sued by some of their clients who developed dermatitis as a result of the chemicals used in the curing of pelts. This was clearly a chemical liability.

At the outset I pointed out that chemical liabilities were an exciting and suitable challenge to consider. I would stress in closing that they are vital to consider. There is a saying that we should not consider challenges as problems but as opportunities.

There is certainly ample opportunity to develop both coverage and legal provisions in such a way that the problems and potential disasters of our time fall within the insurable volume. 